\title{
Teacher requirements in the new educational paradigm
}

\author{
N.A. Savotina ${ }^{1 *}, M . V$. Reimer $^{2}$, and A.S. Kyvyrzhik ${ }^{3}$ \\ ${ }^{1}$ Kaluga State University named after K.E. Tsiolkovsky, Kaluga, Russia \\ ${ }^{2}$ Kaluga State University named after K.E. Tsiolkovsky, Kaluga, Russia \\ ${ }^{3}$ Kaluga State University named after K.E. Tsiolkovsky, Kaluga, Russia
}

\begin{abstract}
This article presents a professional portrait of a history teacher of a secondary school, based on the requirements of state standards for the level of professional competence of the teacher. According to the results of our research, the content components of the professional portrait were such indicators as motivation, attitude to innovative technologies, level of professional training, personal pedagogical qualities, level of pedagogical tolerance and empathy.
\end{abstract}

\section{A problem statement}

The current state of the educational system in the Russian Federation is characterized by significant recent changes which include: An increased emphasis on the study of the humanities; a holistic approach to teaching; the diversification of educational institutions and training programs; the multilevel training of teachers and the widespread use of IT. These cardinal changes necessitate a comprehensive reevaluation of the levels of competence required for teachers who, in this new paradigm, must be able not only to professionally master new teaching technologies, but also to search for new ways of developing the spiritual and moral components of the educational process itself, thus more effectively passing on to students the traditions upon which Russian society is founded.

Responsibility for the implementation of this process lies not only with the individual curriculum-developer. All requirements are strictly set forth in official state government documents pertaining to the field of education (the Law "On Education in the Russian Federation", "Strategy for the Development of Education in the Russian Federation until 2025") The mandates contained in these documents are dictated by the needs of society and state. They also reflect input of many parents and students. It objectively follows from the prevailing social educational needs, formed by the age-old traditions of world pedagogy.

To date, researchers have sufficiently deeply studied the issues that relate to the requirements of a modern teacher, but it should be noted that our knowledge regarding their existing problems, the way of thinking, the degree of readiness to revise the established pedagogical concepts, the perception of new methodological forms and teaching aids is very limited. ... Nevertheless, these real data are extremely important for assessing the

${ }^{*}$ Corresponding author: ipcs-profped@yandex.ru 
understanding of the need to make changes in the education system and pedagogical training of future personnel. The degree of success in the implementation of various reforms in this area and the effectiveness of the educational process, which directly depends on the level of the teacher's training and his ability to perceive and reproduce new teaching technologies, depend on the completeness and objectivity of the available information. It is this need that determines the relevance of our research, the results of which are presented in this article.

\subsection{The objective of the work}

The requirements for those who carried out the responsible mission of the teacher in different eras had their own specifics, but you can see general "cross-cutting requirements", independent of the ideological attitudes of the era. Since the existence of Ancient Egypt, from where the first schools originate, the requirements of the first professional teacher, the Roman rhetorician Mark Fibius Quintilian, to the personal qualities of the teacher consisted in the obligatory improvement of their subject knowledge and traits of their nature throughout their life. Among them, a special place was occupied by love and respect for children, who, according to the ancient Roman orator, ensure effective assimilation of the material.

In the Middle Ages, the famous French writer Francois Rabelais noted that a teacher in his work should rely on the practical experience of students and surround his students with attention and care.

In the first half of the 17th century, the Czech humanist educator Jan Amos Comenius, in his Great Didactics (1657), in spite of the scholasticism that reigned at that time, proposes to organize teaching in visual terms, believing that the truth and reliability of knowledge depends on the senses, which means that from the activity of the student's thought, his independent activity.

At the beginning of the nineteenth century, when specialized pedagogical literature began to be published, and large educational institutions began to appear that train professional teachers [1], the nature of the requirements for the teacher began to change.

In Russia, the first teachers were Greek and Byzantine missionaries who appeared with the adoption of Christianity in the 10th century, and during the reign of Emperor Peter I, teachers from Europe began to be invited to serve, the requirements for which were that foreign teachers taught Russian children languages, exact sciences, manners. Foreign colleagues of our teachers were considered more educated, and, consequently, their knowledge was considered more valuable. Unfortunately, not all of them did their duty properly. The apparently wealthy and intelligent teachers very often turned out to be unreliable and irresponsible. An outstanding teacher of the middle of the 19th century, Konstantin Dmitrievich Ushinsky - "the father of Russian teachers", not only substantiated the didactic principles, without which the didactic system is powerless even today (clarity, scientific, systematic and consistency, conscientiousness, strength, connection with life, etc.), but and makes an attempt to substantiate the social role of the teacher, to raise his authority. In the article "On the Benefits of Pedagogical Literature" (1857) K.D. Ushinsky formulates the basic requirements for the teacher, arguing that the teacher is the most important element in the pedagogical process: “... the influence of the personality of the educator on the young soul is the educational force that can not be replaced by textbooks, moral maxims, or a system of punishments and rewards" [2].

According to Leo Tolstoy, the main mission of a teacher in a free school should be to foster spirituality and humanity in a person.

In the XX century, Anton Semyonovich Makarenko saw the most important task of a teacher and upbringing in preparing a developing personality for social duties, for a certain 
system of dependencies, and teachers, an educational team, as a necessary mediating link between society and the individual [3].

In our time, many scientists in the field of pedagogy, psychologists, methodologists have dealt with the problems of creating a professional portrait of a teacher, among whom the author of the psychological concept of professionalism A.K. Markova, researchers of the process of personality formation in a professional educational space in the unity of psychological and pedagogical components E.F. Zeer, T.A. Zhalagin, V.A. Bodrova and E.A. Klimova and others. Such prominent psychologists as N.A. Aminov, I.A. Zimnyaya, A.A. Kalyuzhny, E.B. Perelygina, V.A. Sonin, and others. N.M. Zverev, O.G. Krasnoshlykova, M.I. Lukyanova, V.A. Korolev devoted their works to the study of the development of the teacher's professional competence. I.V. Prosvirnina and V.A. Tolochek. Well-known methodologists such as E.E. Vyazemsky, P.A. Baranov, M.T. Studenikin and V.V. Shogan consider this issue within the framework of teaching history [4].

In this context, it is worth highlighting the articles by P.A. Baranov "On the model of professional competence of a history teacher" and N.P. Ovchinnikova "Professional portrait of a history teacher: theoretical and practical aspects", which highlight the issues of professional competencies that a history teacher should have in the conditions of the modern education system and his personal qualities necessary for the effective implementation of teaching activities [5].

It is quite obvious that each of the existing narrow specializations of the teaching profession has its own specific characteristics and requirements that are imposed on it. Speaking about the history teacher, one should emphasize his exceptional role in the education and socialization of schoolchildren, because it is he who provides students with invaluable information about the development of human society and its laws, introduces the history of different countries and peoples, which is an important component of national identity, teaches to understand the cause -investigative ties and navigate in various spheres of human life, ranging from the history of military conflicts, ending with culture and art.

In our opinion, the fundamental tasks that a history teacher should set himself in a new educational situation include:

1) Carrying out activities to form a sense of involvement of schoolchildren in the events of the past and present of their country, develop an understanding of the need to preserve historical memory and comply with laws, as well as develop in students such qualities as mercy, compassion, hard work, responsibility, respect and self-respect.

2) Being an example of moral and professional qualities, the teacher should be a mentor and friend for his pupils, guiding them and positively motivating them.

\section{Materials and the results of the research}

The main goal of our research was to study the requirements for a history teacher today, as well as to compare the presented image with a real portrait of a modern teacher. To achieve this goal, we have identified a range of tasks, the most important of which are: analysis of existing scientific literature and legislation governing the requirements in this area; a survey of history teachers; identification of teachers' compliance with the requirements for them, drawing up a professional portrait of a history teacher.

To confirm the theoretical foundations of this study, we conducted an anonymous survey of teachers of the history of secondary schools without reference to a specific locality, in which 78 people with different experience in the field of education took part directly: $12.8 \%$ of respondents have less than 5 years of teaching experience, from 5 to 10 years old - about $23.1 \%$, from 10 to 15 years old - $17.9 \%$, from 15 to 20 years old $-10.3 \%$, from 20 to 25 years old $-15.4 \%$ of teachers, and $20.5 \%$ have more than 25 years of experience in general education. 
The fundamental tasks that a history teacher should set himself in the framework of the modern education system include:

1) Carrying out activities to form a sense of involvement of schoolchildren in the events of the past and present of their country, develop an understanding of the need to preserve historical memory and comply with laws, as well as develop in students such qualities as mercy, compassion, hard work, responsibility, respect and self-respect.

2) Another significant pedagogical task is to be an example of all the above qualities, to be a mentor and friend for your pupils, guiding them and positively motivating them.

3) Each teacher should contribute to the personal development of the student and his self-determination as a full member of society. The results of our survey, in turn, showed that the most significant task in the teaching process of history teachers is the upbringing of a moral personality capable of productive activity and self-realization in the chosen profession - this option was approved by 50 teachers, which is $64.1 \%$ of all respondents. 33 people $(42.3 \%)$ among the significant ones also indicated the task of forming cognitive activity in students, 27 teachers $(34.6 \%)$ - the development of their civic consciousness, and 24 teachers $(30.8 \%)$ - the formation of subject knowledge, skills and abilities (Figure 1).

Education of a moral person capable of selfrealization in the profession, as well as productive activities.

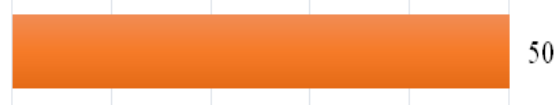

Formation of cognitive activity and motivation for activity

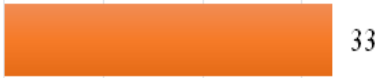

Development of students ' civic consciousness

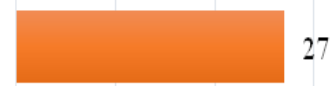

Formation of students' subject knowledge, skills

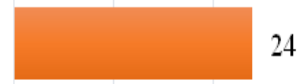

$\begin{array}{lllllll}0 & 10 & 20 & 30 & 40 & 50 & 60\end{array}$

Fig. 1. The most significant tasks in the pedagogical process (survey results).

The personality of a history teacher, as well as the personality of any other subject teacher, is made up of several components, which include, first of all, professional and pedagogical interest and inclination to teaching, positive motives of activity and a professional position based on an awareness of duty and responsibility [6].

The teacher's professional behavior is determined by his personal pedagogical position, motives of activity, the level of general and pedagogical culture, as well as competence in the field of pedagogy and psychology. These components determine their own unique style of each teacher, and that is why professional behavior, among other things, includes such indicators as creativity, conceptuality, individuality [7].

Professional behavior is formed in several stages, the first of which is self-determination and choice of a profession, which is influenced by both the example of parents-teachers and the "pedagogical ideal" of the beloved schoolteacher. According to the survey results, it was personal example that became the decisive factor in choosing a profession for $34.7 \%$ of respondents ( 27 people). The next most popular answer was the possibility of developing one's inclinations and talents through pedagogical activity - this option was chosen by $21.8 \%$ of teachers. The third place was taken by the creative nature of the work $-17.9 \%$ 
voted for it. In addition, love for children influenced the choice of $14.1 \%$ of all respondents, which is 11 people, the authority of parents and relatives - $5.1 \%$, demand in the labor market $-3.8 \%$, prestige in society $-2.6 \% \ldots$ The option "wage level" was not chosen by any of the respondents (Figure 2).

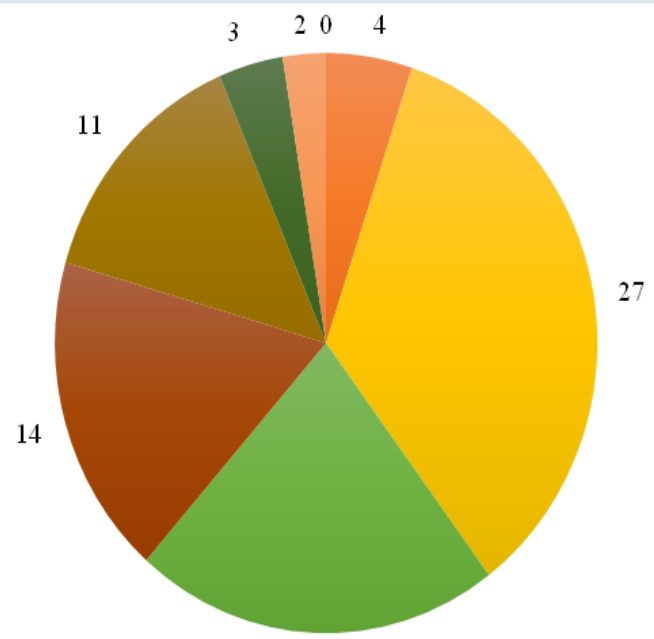

17

- Authority of parents and relatives

- Personal example of a particular teacher

- Opportunity to develop your aptitudes and talents

Creative nature of the work

- Love for children

Demand in the labor market

- Prestige in the society

Wage level

Fig. 2. Factors for choosing a profession (survey results).

The next stage concerns the professional training of the future teacher within the walls of the university, where the formation of reproductive professional behavior and readiness for the implementation of pedagogical activities are ensured, the foundations of an individual style are laid [8]. At the third stage, professional development is ensured in the course of independent teaching, and at the last stage, the completion of the formation of skills for performing the basic functions of a teacher and the development of the ability to satisfy the need for personal development. According to the results of our survey, professional growth and development turned out to be an important component of activity for $97.5 \%$ of teachers (76 people) (Figure 3 ). 


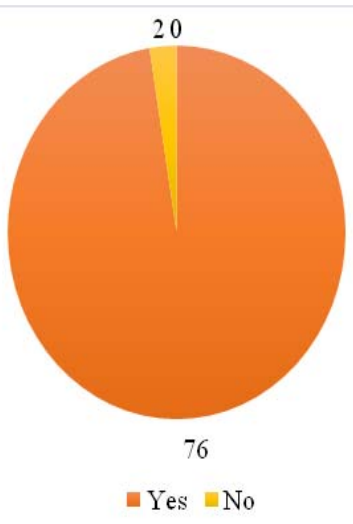

Fig. 3. Professional growth and development of respondents (survey results).

It is worth noting that history teachers provide their professional growth in different ways. So $82.1 \%$ increase the level of professionalism by attending seminars and conferences, $67.9 \%$ prefer to study methodological literature and information and computer technologies, $47.4 \%$ implement professional development by participating in various master classes and competitions, and $26.9 \%$ - conducting open sessions for analysis by colleagues (Figure 4).

Participation in master classes and competitions

Learning IT

Conducting open sessions for peer review

Attending seminars and conferences

Reading of methodological literature
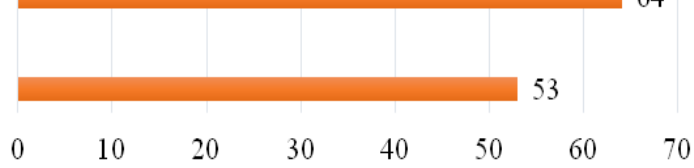

Fig. 4. Professional growth preferences (survey results).

Thus, a high level of professional behavior of a teacher is characterized by the necessary personal and pedagogical qualities, which consist in the acceptance of the student as a subject of his professional activity, organization of the educational process in accordance with state educational standards, taking into account the individual characteristics of each student, independent planning and implementation of educational programs. In their subject and demonstration of a model of behavior at the educational and cultural levels [9].

It must be remembered that the professional behavior of a teacher who has a sufficiently high level of pedagogical culture will always be characterized by the constancy and reasoning of his position, the stability of the principles of activity, as well as the ability to approach the solution of emerging problems with the necessary flexibility and creativity.

Within the framework of the problems under study, it is necessary to pay attention to the importance of the value-semantic orientation of the teacher, who must have a certain 
system of personal values, attitudes and meanings of professional behavior and be able to successfully overcome the identity crisis [10].

It is worth noting that when answering the question about what makes a teacher a professional, 78.2\% (61 people) affirm the importance of deep knowledge in the field of history, $74.4 \%$ (58 people) are sure that the teacher's professionalism directly depends on knowledge and skills in the field of organizational, communicative and reflective activities, $61.5 \%$ (48 people) note the need for general psychological, pedagogical and didactic knowledge and skills, $41 \%$ (32 people) point out the love of children as an important factor, $14.1 \%$ (11 people) - respectful attitude from colleagues and parents, $7.7 \%$ (6 people) compliance with the requirements of state standards, as well as two teachers $(2.6 \%)$ noted the ability to learn on their own and the experience of teaching (Figure 5).

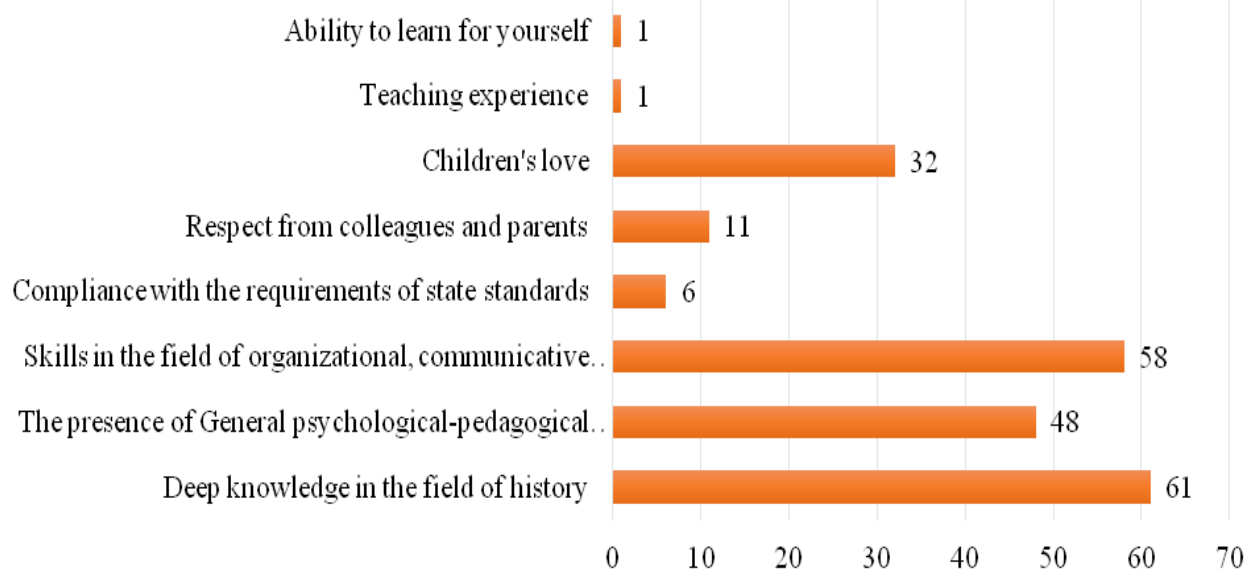

Fig. 5. What makes a teacher a professional (survey results).

The current situation in education encourages history teachers to carry out their activities in a dynamically changing socio-economic situation, which is characterized by a radical revision of previously established moral and ethical values, guidelines and distinctive features of our society. In addition, one cannot but take into account the situation inside Russia, whose pedagogical science is becoming more and more open to the perception of the achievements of Western methodologists, adopting and creating its own concepts and pedagogical technologies. According to the results of our survey, the achievements of foreign pedagogical technologies are actively introduced into the educational process by $9 \%$ of teachers ( 7 people), occasionally they are used in their work $60.3 \%$ (47 people). 17 respondents, which is $21.8 \%$, give preference to domestic technologies and methods, and another $9 \%$ (7 people) are not interested in modern pedagogical technologies at all.

Based on the multicultural nature of the modern educational situation, a history teacher should take into account that students can be representatives of different cultures, confessions and bearers of completely opposite political, ideological and cultural values, and therefore he must have such qualities as tolerance for opinions and views that contradict him. own, openness, willingness to dialogue and understanding of the versatility and ambiguity of the historical process as a whole. According to the survey results, pedagogical tolerance as tolerance for children, the ability to understand and forgive their imperfections is important for $93.6 \%$ ( 73 people) of the respondents, while the remaining $6.4 \%$ (5 people) hold the opposite point of view. 
A history teacher must have a sufficient level of empathy in order to correctly understand the motives of his students' activities, to evaluate and direct their energy in a positive direction and to form a desire to work for the good of society and the state. $92.3 \%$ of respondents ( 72 people) agreed with this statement, $6.4 \%$ (5 people) were against it, and one of the teachers could not unequivocally answer this question.

Of course, with an empathic attitude towards his pupils, the teacher retains the right to personal opinion and expression of his value orientations, which give a special meaning to his professional activity, but he cannot allow them to be imposed on anyone [11].

The transition to civil society as one of the tasks poses for the history teacher to convey to the attention of students, if possible, not only the official, but also alternative points of view on various problems of history and society, which contributes to the formation of a worldview and the ability to defend their own civic position of students [12]. In this regard, it is also effective to draw the attention of students to various debatable issues of history and provide an opportunity to express their own opinion, based on factual material [13].

The widespread introduction of modern information technologies requires from the history teacher the ability to organize the activities of schoolchildren in a new space at a higher level of efficiency [14]. The teacher is no longer the only carrier of information, his functions are increasingly shifting towards the organizer of the cognitive-research process of obtaining objective knowledge by students. It is proved that the role of the knowledge acquired by schoolchildren increases in proportion to their independent work, as a result of which they independently, with the support of the teacher, build cause-and-effect relationships, come to certain conclusions and thereby build their own model of history perception. As a result, the teacher should bring diversity to the traditional educational and methodological complex by introducing information technologies, new video means of transmitting information, techniques and technologies.

\section{Conclusions}

Thus, an important characteristic of the portrait of a modern teacher is innovative activity aimed at strengthening the interest of schoolchildren in the subject, increasing their motivation and level of training. Modern means and technologies of teaching history, leading concepts of history education and their content should be designated as innovative fields of such activity. The teacher should turn his attention to the ideas of developmental and student-centered learning. Thus, among the surveyed history teachers, $65.4 \%$ (51 people) use discussion technology in their work, which consists in finding the truth through discussions and consideration of controversial issues, 50\% (39 people) - research technology (the teacher implements the model of "learning through discovery" ), 48.7\% (38 people) - game (modeling difficulties in the educational space and finding ways to solve them), $44.9 \%$ (35 people) - activity (designing the forthcoming activity, in which the student is its subject), 38, 5\% (30 people) - reflexive (the child's awareness of the activity: the way to achieve the result, difficulties and his emotional state during and after implementation), and 5.1\% (4 people) do not use such technologies.

Based on the list of professional and pedagogical skills of a history teacher, which was compiled by P. A. Baranov, and the results of our survey of history teachers, we can conclude that the following are important in the professional portrait of a history teacher:

- the ability to determine the level of development of students and use such forms and methods of work that would contribute to the gradual development of independence and creativity in performing cognitively problematic tasks in the study of history;

- setting pedagogical goals of varying degrees of difficulty, taking into account the possibilities of the topic of the lesson; 
- the ability to modify the forms of the lesson, using the possibilities of discussion and creating pedagogical situations with methodological, moral and aesthetic content;

- the main goal of planning history lessons should be such a system in which a collision that is significant for students is consistently developed, a problem is posed that requires collective efforts to solve it and encourages students to comprehend philosophical and worldview conclusions based on the studied historical material [5, p. 57-62].

The work of a teacher at all times required constant dedication, a high level of creative thinking, initiative, firm principles and beliefs, today it requires additional flexibility of thinking in the conditions of multicultural education, the ability to effectively reflect and thoroughly analyze the work done [15]. Today, as never before, it is important for a history teacher to realize the level of responsibility that pedagogical activity imposes on him, an understanding of the role of history as an academic subject, a means of educating and socializing a person, as well as the importance of the value of historical experience for an objective assessment of the past, knowledge of the present and forecasting the future.

\section{References}

1. T. D. Potekhina, Discussion in a modern lesson, Yaroslavl pedagogical Bulletin, 4, 117 (2002)

2. K.D. Ushinsky, On the benefits of pedagogical literature, p. 169 (Moscow, Leningrad: Academy of pedagogical Sciences of the RSFSR, 1948-1952)

3. A.V. Komarova, T.V. Slotina, The problem of the individual and the team: modern view through the prism of the ideas of A.S. Makarenko and I.P. Ivanov, Scientific and technical Bulletin of the Saint Petersburg state Polytechnic University. Society. Communication. Education, 1, 132-138 (2014)

4. I.T. Vostrikov, The image of a history teacher in modern russian historiography, Yearbook. XIX all-Russian historical and pedagogical readings, 2, 33-42 (2015)

5. P.A. Baranov, On trends in the development of modern school historical education, Teaching history and social studies at school, 9, 57-62 (2005)

6. P.G. Postnikov, Professional behavior of teachers: psychological and pedagogical analysis, Pedagogy, 5, 51-56 (2004)

7. N.P. Ovchinnikova, Professional portrait of a history teacher: theoretical and practical aspects, Teaching history and social studies at school, 5, 52-58 (2004)

8. K.E., Zvereva, S.V. Inozemtseva, Teaching profession through the eyes of beginners: touches to the professional portrait of a modern history teacher, p. 193-200 (Cases and days: Siberia, Russia, the world in the research and educational space, 2017)

9. T.A. Sinelnikova, Portrait of a teacher as a collective image of research by scientists, psychologists, and students themselves, p. 276-278 (Pedagogical skills: materials of the V International scientific conference, Moscow, 2014)

10. A.G. Ovodova, Image of a modern teacher, Primary school plus before and after, 5, 26-30 (2004)

11. E.P. Ilyin, Dynamics of emotional sphere and aggressiveness characteristics during the period from youth to old age, Bulletin of practical psychology of education, 4, 42-46 (2007)

12. D.V. Kuzin, Preparing a history and social studies teacher for a new school, Universum: Bulletin of the Herzen University, 1, 102-106 (2010)

13. M.Y. Burtseva, Using discussions in history lessons, Problems of modern science and education, 1, 173-175 (2013) 
14. P.A. Baranov, On the model of professional competence of a history teacher, Teaching history and social studies at school, 3, 21 (2001)

15. I.I. Sokolova, Socio-professional portrait of the teacher, Universum: Bulletin of the Herzen University, 2, 3-14 (2010) 